\title{
Of BoOKs And Bijou: The Poet's LetTer to Katherine
}

\author{
Christine Stewart-Nuñez
}

Wedding bliss subsided. To quell homesickness, Henry VII invited you to Richmond, hosted your ladies in his new library. Bookish Infanta! He planned to please you with words penned in Latin, English. To seal his success, velvet boxes opened: brooches set with sapphires and pearls, carcanets of emeralds, habillaments of diamond and topaz, ruby rings. Choose your heart's desire, he said. After Arthur's death, your mother-in-law tried to assuage your sorrow by sending you more books and a barge to sail for Court. Yet bransles dances and delectable meat-pies at Richmond didn't work. You rorote you heart's desire. I imagine you sat as I do now, heavy-eyed, elbow on oak, chin resting on your palm, fingertips of your free hand poised to ink the page. How the thrill of the chasing down the right word suits us. We both dare not write the truth in plain writing. For me, the puzzle of marrying image and sound; for you, daughter-diplomat, the cipher of shape and code: Rs disguised as $7 \mathrm{~s}$, Cs as + and Ys as $\varnothing$. Perhaps a day at your desk decorated your hand with a garnet of ink; mine ends with pear-shaped impressions. Even after we've closed the day's page, our minds search for sharp sparkle and cut of phrase, those handsome sets of persuasion. 